\title{
Role of neutrophil-lymphocyte ratio in determining the outcomes of preterm premature rupture of membranes
}

\author{
M. P. A. Sai Lakshmi, V. Lakshmi Sravani*
}

Department of Obstetrics and Gynecology, Rajarajeswari medical college and hospital, Bangalore, Karnataka, India

Received: 01 February 2021

Revised: 10 March 2021

Accepted: 11 March 2021

\section{*Correspondence:}

Dr. V. Lakshmi Sravani,

E-mail: lakshmi.sravani48@gmail.com

Copyright: (C) the author(s), publisher and licensee Medip Academy. This is an open-access article distributed under the terms of the Creative Commons Attribution Non-Commercial License, which permits unrestricted non-commercial use, distribution, and reproduction in any medium, provided the original work is properly cited.

\section{ABSTRACT}

Background: Premature Rupture of Membranes (PROM) is a significant obstetric problem. Evaluation of neutorphillymphocyte ratio (NLR) is expected to throw light on the potential scope of early prediction of PPROM. With this background, the present study was carried out to compare the NLR among preterm PROM and healthy controls to evaluate the predictive role of NLR and platelet-lymphocyte ratio (PLR).

Methods: This case control study was carried out among 101 pregnant women 44 pregnant women diagnosed with Preterm PROM and 55 term gestation matched healthy controls. Laboratory parameters (including complete blood count were measured. PLR was calculated as the number of platelets divided by the lymphocyte count, and NLR was calculated by dividing the neutrophil Count by the lymphocyte count, both of which were obtained from the same blood samples.

Results: All the inflammatory markers including total count, neutrophil count, NLR and PLR ratios were elevated among PPROM group compared to the controls. The observed differences in the mean levels of these parameters were statistically significant $(\mathrm{p}<0.05)$.

Conclusions: It may be considered that monitoring of NLR during second and early third trimesters as a routine practice among high risk mothers can significantly help in early prediction of PPROM and help in minimizing adverse maternal and neonatal outcomes.

Keywords: Inflammatory markers, Neutrophil lymphocyte ratio, Platelet lymphocyte ratio, Premature rupture of membranes

\section{INTRODUCTION}

Pre-term premature rupture of membranes (PPPROM) is an alarming condition in pregnancy, complicating 3\% of all pregnancies. ${ }^{1}$ It is defined as spontaneous rupture of membranes before the onset of labour, prior to 37 weeks. This often leads to adverse maternal outcomes including chorioamnionitis, endometiritis and post-partum hemorrhage. ${ }^{2}$ Among the neonates, further complications including preterm labour, fetal distress and admissions in neonatal intensive care unit (NICU) increase the morbidity and mortality among neonates. Overall, PPROM is associated with a wide range of morbidities, mortality, disability including socioeconomic disability. ${ }^{3}$

Several maternal causes have been attributed to PPROM including recurrent urinary tract infections, sexually transmitted diseases and low socioeconomic status. Although these causes have been implicated as potential risk factors of PPROM, the actual triggering factor for early rupture of membranes continues to remain unknown. ${ }^{4}$ Therefore, predicting the risk of PPROM early during pregnancy has been a challenge. 
Overall, it has been hypothesized that presence of chronic inflammation could trigger premature rupture. Several inflammatory markers have been evaluated in the pathogenesis of PPROM and there are evidences which show increased proliferation of megakaryocytic series and the severe apoptosis is associated with decreased lymphocyte counts. ${ }^{5}$ Therefore, evaluation of neutorphillymphocyte ratio (NLR) is expected to throw light on the potential scope of early prediction of PPROM. With this background, the present study was carried out to compare the NLR among preterm PPROM and healthy controls to evaluate the predictive role of NLR and plateletlymphocyte ratio (PLR).

\section{METHODS}

\section{Study setting and participants}

This case control study was carried out among 101 pregnant women admitted to the Department of Obstetrics and Gynecology of Rajarajeswari Medical College and Hospital for a period of six months between July 2019 and December 2019. The study participants consisted of 44 pregnant women diagnosed with Preterm PPROM and 55 term gestation matched healthy controls. The study participants were selected by purposive sampling.

\section{Data collection}

Samples of peripheral venous blood were drawn from the antecubital vein on admission (before administration of betamethazone and antibiotic prophylaxis) and studied at the laboratory within 1-3 hours. Laboratory parameters (including complete blood count, C-reactive protein (CRP) of all the participants were recorded. Blood samples were taken into standardized tubes containing dipotassium ethylenedinitro tetraacetic acid (EDTA) for complete blood count (CBC), which was done using a LEICA autoanalyser sysmex XN 1000. The PLR was calculated as the number of platelets divided by the lymphocyte count, and NLR was calculated by dividing the neutrophil Count by the lymphocyte count, both of which were obtained from the same blood samples.

\section{Data analysis}

Data was entered and analyzed using SPSS ver.23 software. The parameters of NLR and PLR were expressed as mean and their differences between cases and controls were analyzed using Independent sample $\mathrm{t}$ test. A $\mathrm{p}$ value $<0.05$ was considered statistically significant.

\section{RESULTS}

Majority of the cases (PPPROM) were primigravida $(54.5 \%)$ while among the controls, majority were multigravida $(52.7 \%)$. Majority of the participants in PPPROM were aged between 21-25 years (56.8\%) followed by $26-30$ years $(38.6 \%)$. Among the controls, $69.1 \%$ of the participants were aged $<25$ years. With regards to the birth weight of the newborns, majority of the newborns born to mothers with PPPROM weighed $<2500$ grams $(75 \%)$ in comparison to $7.3 \%$ among the controls. Normal birth weight (2500-3000 grams) was seen among $22.7 \%$ of PPPROM mothers and $45.5 \%$ of the controls (Table 1).

Table 1: Demographic particulars of the study participants.

\begin{tabular}{|lll|}
\hline Characteristics & \multicolumn{1}{c|}{$\begin{array}{c}\text { PPPROM } \\
\text { N }(\%)\end{array}$} & $\begin{array}{l}\text { Controls } \\
\text { N }(\%)\end{array}$ \\
\hline Age of the mothers (in years) & \\
\hline$<\mathbf{2 5}$ & $25(56.8)$ & $38(69.1)$ \\
\hline $\mathbf{2 5 - 3 0}$ & $17(38.6)$ & $17(30.9)$ \\
\hline$>\mathbf{3 0}$ & $2(4.5)$ & $0(0)$ \\
\hline Birth weight (in grams) & $4(7.3)$ \\
\hline$<\mathbf{2 5 0 0}$ & $33(75)$ & $25(45.5)$ \\
\hline $\mathbf{2 5 0 0 - 3 0 0 0}$ & $10(22.7)$ & $26(47.3)$ \\
\hline$>\mathbf{3 0 0 0}$ & $1(2.3)$ & \\
\hline
\end{tabular}

Table 2: Comparison of laboratory parameters between cases and controls.

\begin{tabular}{|c|c|c|c|c|c|c|}
\hline Parameter & Groups & $\mathbf{N}$ & Mean & S.D & T value & $P$ value \\
\hline \multirow{2}{*}{ Hemoglobin } & Controls & 55 & 11.43 & 1.08 & \multirow{2}{*}{2.542} & \multirow{2}{*}{$0.013^{*}$} \\
\hline & PPPROM & 44 & 10.7 & 1.62 & & \\
\hline \multirow{2}{*}{ Total count } & Controls & 55 & 12423.8 & 3788.54 & \multirow{2}{*}{3.458} & \multirow{2}{*}{$0.001^{*}$} \\
\hline & PPPROM & 44 & 15302.7 & 4492.75 & & \\
\hline \multirow{2}{*}{$\begin{array}{l}\text { NeutrophilCount (cells } \\
\text { per cubic millimeter) }\end{array}$} & Controls & 55 & 9283.09 & 3564.77 & \multirow{2}{*}{3.852} & \multirow{2}{*}{$0.0005^{*}$} \\
\hline & PPPROM & 44 & 12381.4 & 4439.8 & & \\
\hline \multirow{2}{*}{$\begin{array}{l}\text { Platelet Lymphocyte } \\
\text { ratio (PLR) }\end{array}$} & Controls & 55 & 106.26 & 35.36 & \multirow{2}{*}{2.315} & \multirow{2}{*}{$0.024 *$} \\
\hline & PPPROM & 44 & 132.96 & 69.64 & & \\
\hline \multirow{2}{*}{$\begin{array}{l}\text { Neutrophil lymphocyte } \\
\text { ratio (NLR) }\end{array}$} & Controls & 55 & 4.22 & 2.09 & \multirow{2}{*}{3.848} & \multirow{2}{*}{$0.0005^{*}$} \\
\hline & PPPROM & 44 & 6.66 & 3.75 & & \\
\hline
\end{tabular}


It was observed that the mean hemoglobin levels were lower for the PPPROM group $(10.7 \mathrm{~g} \%)$ compared to the healthy controls $(11.43 \mathrm{~g} \%)$. The observed difference was statistically significant $(\mathrm{p}<0.05)$. However, all the inflammatory markers including total count, neutrophil count, NLR and PLR ratios were elevated among PPPROM group compared to the controls. The observed differences in the mean levels of these parameters were statistically significant $(\mathrm{p}<0.05)$ (Table 2$)$.
On comparing the neonatal admissions between PPPROM (cases) and controls, it was observed that neonates born to PPPROM mothers had increased NICU admissions (11.4\%) compared to normal controls $(0 \%)$. The observed difference was statistically significant (Table 3).

Table 3: NICU admissions- Comparison of neonatal outcomes between cases and controls.

\begin{tabular}{|c|c|c|c|c|c|c|c|}
\hline \multicolumn{8}{|c|}{ Comparison between NICU with Groups } \\
\hline & & & \multicolumn{2}{|l|}{ Groups } & \multirow[b]{2}{*}{ Total } & \multirow{2}{*}{$\begin{array}{l}\text { Chi sq } \\
\text { value }\end{array}$} & \multirow[b]{2}{*}{ P-value } \\
\hline & & & Controls & $\begin{array}{l}\text { PPPRO } \\
\text { M }\end{array}$ & & & \\
\hline \multirow{4}{*}{ NICU } & \multirow{2}{*}{ No } & Count & 55 & 39 & 94 & \multirow{6}{*}{6.582} & \multirow{6}{*}{$0.015 *$} \\
\hline & & $\%$ & $100.0 \%$ & $88.6 \%$ & $94.9 \%$ & & \\
\hline & \multirow{2}{*}{ Yes } & Count & 0 & 5 & 5 & & \\
\hline & & $\%$ & $0.0 \%$ & $11.4 \%$ & $5.1 \%$ & & \\
\hline \multirow{2}{*}{ Total } & & Count & 55 & 44 & 99 & & \\
\hline & & $\%$ & $100.0 \%$ & $100.0 \%$ & $100.0 \%$ & & \\
\hline
\end{tabular}

* Statistical Significance at $\mathrm{P}<0.05$ level

Table 4: Birth weight.

\begin{tabular}{|c|c|c|c|c|c|c|}
\hline \multicolumn{7}{|c|}{ Birth weight comparison between Groups by Unpaired T-Test } \\
\hline & & $\mathbf{N}$ & Mean & S.D & t-value & P-value \\
\hline \multirow{2}{*}{$\begin{array}{l}\text { Baby } \\
\text { weight }\end{array}$} & Controls & 55 & 3.04 & 0.33 & \multirow{2}{*}{8.370} & \multirow{2}{*}{$\begin{array}{l}0.0005 \\
* *\end{array}$} \\
\hline & PPPROM & 44 & 2.24 & 0.56 & & \\
\hline
\end{tabular}

** Highly Significant at $\mathrm{P}<0.01$ level

The mean birth weight among PPPROM was lower (2.24 $\mathrm{kg})$ compared to controls $(3.04 \mathrm{~kg})$. The observed difference was statistically significant $(\mathrm{p}<0.0005)($ Table 4).

\section{DISCUSSION}

PPPROM has been established as a significant risk factor for various morbidities in the new born. However, there has been no single predictor of PPPROM, making the clinical management a significant challenge. The mainstay in the etiopathogenesis of PPPROM has been inflammation. Extensive research has been carried out to evaluate the role of inflammatory mediators in the PPPROM. The present case control study was carried out among pregnant women above 18 years and majority of the women in both PPPROM and control groups belonged to the age group of 21-25 years. On analyzing the laboratory parameters, it was observed that the mean values of total counts, neutrophil counts, platelet lymphocyte ratio and neutrophil lymphocyte ratio were elevated among the cases (pregnant women with PPPROM) compared to healthy gestation age matched controls. The observed difference in the mean values between the groups were statistically significant. Similar findings were observed in a study done by Toprak E et al, where women with PPPROM demonstrated elevated
NLR and PLR ratios compared to normal controls. ${ }^{5}$ Another study done by Ozel A et al also demonstrated similar findings showing elevation in the NLR ratio among PPPROM. ${ }^{6}$

The present study has elucidated the role of inflammation in PPPROM, significantly demonstrating the elevation in various inflammatory indicators including NLR and PLR as significant predictors of PPPROM. However, being a case control study, the present study could not demonstrate the effectiveness of these predictors in relation to time. Studies done by Toprak E et al and Ozel A et al further demonstrated predictive efficacy of PLR in early prediction of PPPROM. It was observed from those studies that PLR showed lower sensitivity and specificity (57.8\% and $73.7 \%$ respectively) compared to NLR $(69.7 \%$ and $72 \%$ respectively). 5,6 Therefore, it may be interpreted that although both NLR and PLR stand elevated in PPPROM, the predictive accuracy is higher for NLR compared to PLR. Although the exact pathophysiology behind the predictive role of NLR and PLR in predicting PPPROM is not known, studies have shown that the role antenatal infections including recurrent urinary tract infections and sexually transmitted disease could trigger the inflammatory response, thereby causing PPPROM. ${ }^{7,8}$ 
The present study has also emphasized the increased incidence of adverse neonatal outcomes among PPPROM mothers, namely increasing admissions in the Neonatal Intensive Care Unit (NICU) (11.4\%) compared to 0\% admissions among healthy controls $(\mathrm{p}<0.05)$, and, low birth weight, which was significant in the PPPROM group compared to normal healthy controls $(\mathrm{p}<0.05)$. Study done by Dhannapaneni $\mathrm{N}$ et al effectively outlined the maternal and neonatal outcomes of PPPROM, and the findings were similar to the present study. ${ }^{9}$

\section{CONCLUSION}

Presence of inflammation is the cornerstone in the pathogenesis of PPPROM. The present study effectively demonstrated elevation in both PLR and NLR, in addition to other inflammatory markers including total counts and neutrophil counts. Furthermore, the present study has also emphasized on the impact of PPPROM on neonatal outcomes, significantly outlining the increased need for NICU admissions. Therefore, it may be considered that monitoring of NLR during second and early third trimesters as a routine practice among high risk mothers can significantly help in early prediction of PPPROM and help in minimizing adverse maternal and neonatal outcomes.

Funding: No funding sources Conflict of interest: None declared

Ethical approval: The study was approved by the Institutional Ethics Committee

\section{REFERENCES}

1. Gibbs R, Karlan B, Haney A, Nygaard I. Danforth's obstetrics and gynecology. 10th ed. Philadelphia: Lippincott Williams \& Wilkins; 2008.

2. Caughey AB, Robinson JN, Norwitz ER. Contemporary diagnosis and management of Preterm
Premature Rupture of Membranes. Rev Obstet Gynecol. 2008;1(1):11-22.

3. Assefa NE, Berhe H, Girma F, Berhe K, Berhe YZ, Gebreheat $G$, et al. Risk factors of premature rupture of membranes in public hospitals at Mekele City, Tigray, a case control study. BMC Pregnancy and child birth. 2018;18:386.

4. Georgiou HM, Di Quinzio MKW, Permezel M, Brennecke SP. Predicting preterm labour: Current status and future prospects. Disease Markers. 2015:435014.

5. Toprak E, Bozkurt M, Çakmak BD, Özçimen EE, Silahlı M, Yumru AE et al. Platelet-to-lymphocyte ratio: A new inflammatory marker for the diagnosis of preterm premature rupture of membranes. J Turk Ger Gynecol Assoc. 2017;18(3):122-6.

6. Ozel A, Davutoglu EA, Yurtkal A, Madazli R. How do platelet-to-lymphocyte ratio and neutrophil-tolymphocyte ratio change in women with preterm premature rupture of membranes, and threaten preterm labour? J Obstet Gynaecol. 2020;40(2):1959.

7. Usha RS, Vidyayini R, Padmanaban S. Perinatal outcome in pregnancies with preterm premature rupture of membranes inclusive of extreme preterm. International J Clinic Obstetr Gynecol. 2019;3(2):14.

8. Murthy S, Godinho MA, Guddattu V, Lewis LES, Nair SN. Risk factors of neonatal sepsis in India:a systematic review and meta analysis. PLoS One. 2019;14(4):e0215683.

9. Dannapaneni N, Oleti T, Surapaneni T, Sharma D, Murki S. Immediate neonatal outcomes of preterm infants born to mothers with preterm pre-labour rupture of membranes. Indian $\mathrm{J}$ Med Res. 2017;146(4):476-82.

Cite this article as: Lakshmi MPAS, Sravani VL. Role of neutrophil-lymphocyte ratio in determining the outcomes of preterm premature rupture of membranes. Int J Reprod Contracept Obstet Gynecol 2021;10:1617-20. 